\title{
Accident Occurrence and Functional Health Patterns: A Pilot Study of Relationships in a Graduate Population
}

\author{
Fintan K. Sheerin, RNID, MA, PhD, FEANS, Elizabeth Curtis, RGN, MA, MEd, PhD, and \\ Jan de Vries, MSc, PhD
}

Fintan K. Sheerin, RNID, MA, PhD, FEANS, is a Lecturer in Intellectual Disability at School of Nursing and Midwifery, University of Dublin, Trinity College Dublin, Dublin, Ireland; Elizabeth Curtis, RGN, MA, MEd, PhD, is a Lecturer in Nursing at School of Nursing and Midwifery, University of Dublin, Trinity College Dublin, Dublin, Ireland; and Jan de Vries, MSc, PhD, is a Lecturer in Psychology at School of Nursing and Midwifery, University of Dublin, Trinity College Dublin, Dublin, Ireland.

\section{Search terms:}

Accident proneness, FHPAST,

functional health patterns

\section{Author contact:}

sheerinf@tcd.ie, with a copy to the Editor: journal@nanda.org

Part of this study was presented at the 8th Biennial Conference of the Association for Common European Nursing Diagnoses, Interventions and Outcomes 2011.
PURPOSE: This pilot study sought to examine the relationship between functional health patterns and accident proneness.

METHODS: A quantitative-descriptive design was employed assessing accident proneness by collecting data on the occurrence of accidents among a sample of university graduates, and examining this in relation to biographical data and information collated using the Functional Health Pattern Assessment Screening Tool (FHPAST). Data were analyzed using descriptive and inferential statistics.

FINDINGS: One FHPAST factor predicted more frequent sports accidents. Age was also shown to be a significant predictor but in a counterintuitive way, with greater age predicting less accident proneness.

CONCLUSION: The FHPAST may have a role to play in accident prediction.

IMPLICATIONS FOR NURSING PRACTICE: Functional health pattern assessment may be useful for predicting accidents.

\section{Introduction}

Accidents are costly, both monetarily (healthcare bills, loss of productivity, and time) and in terms of human suffering. In many cases, irreparable damage is done, and often, unexpected costs are incurred. Research findings demonstrate that the accumulated cost of accidents is frequently much higher than could have been predicted from the incident itself (Hrymak \& Pérezgonzález, 2007; Mossink \& De Greef, 2002), and that accidents are among the main causes of death and serious injury in children and adolescents (King et al., 2005). In light of this, further insights from research may assist in finding ways to reduce risk of accidents and avert accidents in the future. For the purpose of this research, accident occurrence is defined as the phenomena of unexpected events causing harm to an individual (Niza, Silva, \& Lima, 2008).

Prediction of accident occurrence and assessment of risk is based on the premise that accidents in general are not due to chance alone (Visser, Pijl, Stolk, Neeleman, \& Rosmalen, 2007), and focuses specifically on analyzing circumstances and factors that affect the risk of accidents. The human factor is one of these. One perspective on how circumstances present a risk of accidents to humans emphasizes how the human system in general is prone to making errors in particular circumstances. Another perspective incorporates individual differences in proneness to accidents in the equation.

Recent research has shown, for instance, that car crashes could be predicted from a risk-taking personality trait, sensation-seeking, normlessness, and 
driver anger (Iverson \& Rundmo, 2002). Research also suggests that physiological aspects, such as laterality (Bhushan \& Khan, 2006), organic illnesses (Engel, 1991), and socioeconomic status (Neeleman, 2001), may play a role. Furthermore, in children, it has been found that high energy levels, optimism, and introversion predicted involvement in accidents (Barkley, 2002; Vollrath \& Torgersen, 2002). A review and meta-analysis of studies of this kind (Visser et al., 2007) comes to the conclusion that accident proneness is an important and "real" issue, and that "accidents cluster in individuals" (p. 562).

Research on health in general, as a predictor of accident proneness, was remarkably underrepresented in the Visser et al. (2007) meta-study. While some studies explored specific behaviors, such as smoking (Altarac et al., 2000) and alcohol use (Hingson \& Howland, 1993), none focused on more general patterns of health. The present study is an effort to address this gap in the research. In doing so, it addresses the conceptualization of health and accident risk within the context of the health belief model (Rosenstock, 1966), which has been described as "an expectancy-value theory" in which an individual focuses on the threat of developing a health condition (including its consequences) and on evaluating the balance between perceived benefits and barriers in adopting a health behavior (Buglar, White, \& Robinson, 2010, p. 269). This conceptual framework was congruent with the theory that was emerging from the literature, and provided a perspective within which to understand functional behavior and its effect on accident occurrence. In keeping with this, the Functional Health Pattern Assessment Screening Tool (FHPAST) was chosen to establish general levels of health behavior through the employment of Gordon's (1994) functional health patterns (FHPs). It is hypothesized that healthier participants would have fewer accidents, but that demographics, behavioral, cognitive, and personality factors may play an important role as regressors. The choice of population for this pilot study was based on the need for all ages and both genders to be involved. The graduate population that the researchers had access to, via the university alumni E-zine, fits this description. Furthermore, proneness to accidents has been examined with a variety of populations, including army recruits (Altarac et al., 2000), hospital patients (Marušič, Musek, \& Gudjonsson, 2001), bus drivers (Blasco, Prieto, \& Cornejo, 2003; af Wåhlberg \& Dorn, 2009), burn victims (Pavan et al., 2009), railway workers (Gauchard, Mur, Benamghar, Dehaene, \& Chau, 2006), and ethnic groups (Bruckner, Brown, \& Margerison-Zilko, 2011). However, while Bruckner et al. (2011) noted the linear relationship among educational achievement, increased money, vehicle ownership, and accident proneness, no studies were found that explored any direct relationship between educational achievement and accident proneness.

It follows, therefore, that further study of accident proneness may also benefit from efforts to address populations not included in research so far, that is, a graduate population.

\section{Aims and Research Questions}

The aim of this study was to (a) identify the proneness for accidents in a population of university graduates; and (b) explore potential associations among biographical data, accident proneness, and functional health. To achieve this aim, three research questions were formulated.

\section{Research Questions}

1. What are the types of accidents that occur among a sample of university graduates?

2. What is the relationship between type of accidents and FHP?

3. What is the relationship between biographical factors such as age and proneness to accidents? 


\section{Methods}

\section{Study Design}

The design chosen for this study was a quantitative-descriptive survey. In this design, the focus is mainly on examining specific characteristics of respondents from a particular population. In this study, the researchers wished to examine the relationship between accident history, as a measure of accident proneness, FHP, and demographic or biographical aspects.

\section{Sample and Sample Size}

A self-selecting sample of 67 graduates was recruited electronically via the electronic magazine of a large Dublin-based university. This was mediated by the alumni office of the university, which acted in the role of gatekeeper. As the form was to be completed online via a third party, the researchers had no access to individual respondents, and thus anonymity was maintained. Information about the study was available via a web link, and consent was implied by completion of the online anonymous survey. The principal criterion for inclusion was that respondents had to be registered with the alumni office of the university. A further advertisement was placed on the university's closed-access Facebook site. As this was a pilot study, there was no attempt to draw generalizations from the findings.

\section{Data Collection Methods}

Data were collected via an online questionnaire survey using the FHPAST developed by Dorothy Jones and Frances Foster based on the work of Gordon's 11 FHPs (Gordon, 1994). Permission to use this tool was given by the authors. Accident proneness was assessed by collecting data via a survey on the occurrence of accidents among the sample, and exploring the relationship between this, biographical data and information collated on the individuals' FHPs. Data collection was undertaken from July until the end of November 2010.

\section{Description of Questionnaire}

This survey questionnaire collected data on the frequency and types of accidents, as well as on biographical, physiological, behavioral, and health factors. The questionnaire was divided into three sections: (a) biographical factors which contained 10 items; (b) accident history which was made up of four items; and (c) FHPs comprising 58 Likert-type items. The biographical factors included age group, gender, handedness, marital status, ethnic group, country of residence, urban or rural setting, academic qualifications, employment status, type of work, and income. Accident history included questions such as number of accidents in the last 5 years, categories of accidents, and events that contributed to accidents. An accident was defined as an event that led to injuries requiring medical care (as suggested in the metastudy on the topic by Visser et al., 2007), and events were classified as traffic, work, sports, and home accidents. The FHP scale had four response alternativesnever, sometimes, often, and routinely. The 58 items contained in this section were divided into two main categories: (a) items indicative of good health, mental health, and healthy lifestyle; and (b) items relating to problems associated with health and mental health. There is limited literature reporting on the psychometrics of the FHPAST. The developers of the tool reported an overall internal consistency of $\alpha=0.91$ (Jones, 2002; Jones \& Foster, 1999, 2006). A further study reported reliability of 0.94 (de Barros, Michel, \& da Nobrega, 2003).

\section{Data Analysis}

All questionnaires were screened for completeness before entry into an SPSS data file. Data were analyzed using both descriptive and inferential statistics. 
Descriptive statistics included frequencies, means, and standard deviations. Data from the FHP section of the questionnaire were analyzed using $t$ tests and multiple regression procedures.

\section{Ethical Considerations}

Respondents were adequately informed about the aim and justification for the study through a cover letter and respondent information sheet. Anonymity was maintained throughout the study given that the questionnaire was completed online with no direct contact between respondents and the researchers. The study was granted ethical approval by a facultybased Ethics Review Committee in 2010, prior to commencement of data collection.

\section{Findings}

Analysis of the data was performed using SPSS version 16.0 (SPSS Inc., Chicago, IL, USA). While a total of 67 potential participants accessed the online tool, 49 proceeded to participate. They completed the section on biographics and accident proneness. A further six did not complete the last section which included the FHPAST. The full instrument was, therefore, completed by 43 participants.

\section{Description of the Sample}

Women were overrepresented in the sample with $33(67.3 \%)$ responding, leaving only $32.7 \%(n=16)$ males. Almost $60 \%(n=29)$ of respondents were between 25 and 34 years of age, with the remainder mostly in the proximal age groups. Only $8 \%(n=4)$ was over 55 years of age. There was a relatively equal spread across relationship status with $32.7 \%(n=16)$ single, $36.7 \%(n=18)$ having a partner and $30.6 \%$ $(n=15)$ married. The cultural character/ethnicity of the sample was labeled according to Irish census standards. Respondents identified themselves as follows: white Irish $(n=45,90 \%)$; white non-Irish $(n=4,10 \%)$.
No one identified as black Irish/non-Irish, Asian Irish/ non-Irish, or of mixed background. The majority of participants $(n=28)$ described themselves as living in an urban environment, with 18 (57.1\%) living in suburban (36.7\%) and 3 in rural settings (6.1\%). Twentytwo participants (44.9\%) had, as their highest academic achievement, an undergraduate degree, while the remainder held diplomas $(n=6,12.3 \%)$, master's degrees ( $n=15,30.6 \%)$, and doctorates $(n=6,12.2 \%)$. Of the majority of participants who described themselves as "employed" ( $n=40,83.3 \%)$, almost half of the participants ( $n=22,46.8 \%)$ perceived their work to be in the ranks of "higher professionals," while 11 (23.4\%) categorized it as "lower professional," with 5 (10.6\%) identifying themselves as "employers or managers." The kind of work participants reported varied, with researchers somewhat overrepresented $(n=8,12 \%)$. The remaining respondents were unemployed $(n=4,8.3 \%)$ or retired $(n=4$, $8.3 \%$ ). Last, the handedness of the sample is more or less representative of the general population: right handed $(n=45,92 \%)$; left handed $(n=4,8 \%)$.

\section{Accident Proneness Within the Sample}

Approximately $40 \%$ or the participants $(n=20)$ reported having had accidents in the last 5 years, while $60 \%$ reported that they had not $(n=29)$. Traffic and work accidents were each reported by only one participant, while 10 participants reported sports accidents and 13 participants reported accidents taking place in the home. Whereas most participants reported one or two accidents, five participants reported three to six (Table 1).

More specifically participants were asked to categorize the accidents that they had experienced as caused by specific events. Falls were most common $(n=24)$, followed by cuts $(n=14)$. Burns and scalds were mentioned three times, and motor vehicles, bites or stings, and machinery once each. Two variables were considered indicators for accident proneness: 
Table 1. Types of Accidents and Number of Accident Types Reported by Respondents

$\begin{array}{lccccc} & \mathbf{1 - 2} & \mathbf{3 - 4} & \mathbf{5 - 6} & \mathbf{> 6} & \text { Total } \\ \text { Traffic } & & 1 & & & 1 \\ \text { Work } & 1 & & & & 1 \\ \text { Sports } & 8 & & 1 & 1 & 10 \\ \text { Home } & 11 & 1 & & 1 & 13\end{array}$

1. Accidents (yes/no): The answer to the question whether a person had any accidents in the last 5 years provided us with a categorical variable (yes/ no). The relationship between functional health and accidents (yes/no) was assessed through $t$ tests in which accidents (yes/no) was the independent factor.

2. Accident Proneness: The response to the question identifying the number of accidents in each of the four categories. Scores were summated using the mean of each category (i.e., category 5-6 has a mean of 5.5) to create a separate accident proneness score for each category and a total of their summated scores. The latter was used as dependent variable in a multiple regression procedure, which included FHPAST and the main demographic variables.

\section{Response to the FHPAST}

The FHPAST was scored according to the principles set out by the authors. Most importantly, this included inverting the items 40-57 (outcome score = 4 minus initial score) which are phrased negatively, to ensure that in the summation of items to compute the FHPAST score, their impact would be recorded correctly. The summated score was divided by the number of questions to achieve a mean outcome score. In addition, the three factors identified by the tool developers using a factor analysis were used in
Table 2. Descriptive Statistics in This Study for the FHPAST and Its Three Factors

$\begin{array}{lccccc} & \text { N } & \text { Min. } & \text { Max. } & \text { Mean } & \text { SD } \\ & 43 & 1.28 & 3.49 & 2.83 & .38 \\ \text { FHPAST } & 43 & 1.06 & 2.82 & 2.45 & .32 \\ \text { Health risk/threat } & 43 & 1.52 & 3.96 & 3.09 & .48 \\ \begin{array}{l}\text { General well-being and } \\ \quad \text { self-confidence }\end{array} & & & & & \\ \begin{array}{l}\text { Health promotion } \\ \quad \text { protection activity }\end{array} & 43 & 1.15 & 3.77 & 2.80 & .53 \\ \begin{array}{l}\text { Valid N (listwise) } \\ \text { alid }\end{array} & 43 & & & & \\ & & & & & \end{array}$

FHPAST, Functional Health Pattern Assessment Screening Tool; $S D$, standard deviation.

the analysis of our findings. These factors are health risk/threat, general well-being and self-confidence, and health promotion/protection activity.

The descriptive statistics in this study for the FHPAST total mean score and the three factors are presented in Table 2. It is noteworthy that the scores for health risk/threat were lower than those for the other factors. The FHPAST score was close to 3, which on the 4-point scale used $(1=$ never, $2=$ sometimes, $3=$ often, $4=$ routinely) suggests that overall aspects of health were experienced "often." The authors of the FHPAST identify that scores higher than 3 indicate "desirable functional health."

\section{Relationship Between Proneness to Accidents, FHP Questionnaire (FHPAST), and Biographical Variables}

In order to compare FHPAST scores of participants reporting having had accidents with those who reported no accidents, two statistical tests were performed. First, independent $t$ tests were computed using accidents (yes/no) as the independent variable. Outcomes of these $t$ tests showed that there were no significant differences in FHPAST scores between the two groups. Nor were there significant differences between the three factors (Table 3 ). 
Table 3. Independent $t$ test. Independent Variable: Accidents (Yes/No). Dependent Variables: FHPAST and Its Three Factors (Positive and Negative Questions)

\begin{tabular}{|c|c|c|c|c|c|c|c|c|c|c|}
\hline & \multicolumn{2}{|c|}{$\begin{array}{l}\text { Yes accidents } \\
(n=17)\end{array}$} & \multicolumn{2}{|c|}{$\begin{array}{l}\text { No accidents } \\
(n=26)\end{array}$} & \multicolumn{2}{|c|}{$\begin{array}{l}\text { Confidence } \\
\text { interval }\end{array}$} & \multicolumn{3}{|c|}{$\begin{array}{l}\text { Independent samples } \\
t \text { test (two-tailed) }\end{array}$} & \multirow{2}{*}{$\begin{array}{l}\text { Effect } \\
\text { size } \\
r\end{array}$} \\
\hline & Mean & $S D$ & Mean & $S D$ & Lower & Upper & $t$ & df & $p$ value & \\
\hline FHPAST & 2.91 & 0.34 & 2.79 & 0.40 & -.12 & .36 & 1.02 & 41 & .314 (n.s.) & 0.16 \\
\hline Health risk/threat & 2.51 & 0.22 & 2.41 & 0.36 & -.10 & .30 & .99 & 41 & .326 (n.s.) & 0.16 \\
\hline General well-being and self-confidence & 3.16 & 0.49 & 3.04 & 0.48 & -.18 & .43 & .82 & 41 & .417 (n.s.) & 0.13 \\
\hline
\end{tabular}

FHPAST, Functional Health Pattern Assessment Screening Tool; SD, standard deviation.

Second, a multiple regression analysis was performed to identify the impact of biographical and health factors on accident proneness. Initially, the multiple regressions (in Enter Mode) computed only included the FHPAST total score and the main biographical variables. This yielded no significant predictors. In a further effort to establish a relationship among the three factors within the FHPAST, and biographical variables with accident proneness, a regression was performed (still in Enter mode) including, as independent variables, the three factors (health risk/threat, general well-being and self-confidence, and health promotion/protection activity), as well as handedness, gender, marital status, urban/rural, age, employment, and income (Table 4). No interactions were included.

The findings show that, of these variables, only the factor age loaded significantly on the dependent variable accident proneness. This demonstrates that only age is associated with accident proneness in this study, while the other factors appear to be irrelevant. This association suggests that older participants were less prone to accidents. While the predictive value of the equation is limited, and only $15 \%\left(R^{2}=0.15\right)$ of the variance is explained by the factors included in the model, it is striking that the factor significantly related to accident proneness does so in a counterintuitive way. The results suggest that this could be the result of the inclusion of sports-related accidents. This was tested by excluding sports accidents from the accident proneness variable. Performing the same regression now yielded no significant predictors (with age no longer predicting accident proneness in any significant way) this time.

Finally, to positively identify the impact of the aforementioned factors to proneness to sports accidents, an additional multiple regression procedure, using proneness to sports accidents as dependent variable, was performed. The outcome demonstrated that general well-being and self-confidence and age were significant predictors, indicating that younger people with a higher general well-being and selfconfidence were more likely to have sports accidents (Table 5).

The conclusion is that only proneness to sports accidents is predicted by an aspect of the FHPAST, general well-being and self-confidence (Factor 2), with a high score predictive of higher participation in sports, and therefore a higher chance of sports injuries. Higher age also predicts lower proneness to sports accidents. Considering the low number of participants, interaction effects between age and general well-being and self-confidence could not be included in the multiple regressions performed here.

A further important conclusion is that accident proneness in general (not including sports accidents), 
Table 4. Multiple Regression (Enter Mode): Impact of Biographical and Health Factors on Accident Proneness

\begin{tabular}{|c|c|c|c|c|c|}
\hline \multirow[b]{2}{*}{ Model } & \multicolumn{2}{|c|}{$\begin{array}{l}\text { Unstandardized } \\
\text { coefficients }\end{array}$} & \multicolumn{2}{|c|}{$\begin{array}{l}\text { Standardized } \\
\text { coefficients }\end{array}$} & \multirow[b]{2}{*}{ Sig. } \\
\hline & B & Std. error & Beta & $t$ & \\
\hline (Constant) & .961 & 3.795 & & .253 & .802 \\
\hline Age & -1.128 & .443 & -.779 & -2.544 & $.017^{*}$ \\
\hline Gender & .746 & .760 & .189 & .981 & .335 \\
\hline Urban/rural & -.636 & .527 & -.222 & -1.208 & .238 \\
\hline Highest qualification & .097 & .206 & .085 & .472 & .641 \\
\hline Employment & 1.705 & 1.002 & .527 & 1.702 & .100 \\
\hline Income & .043 & .122 & .066 & .353 & .727 \\
\hline Health risk threat & -1.631 & 1.264 & -.280 & -1.290 & .208 \\
\hline General well-being and self-confidence & 1.687 & .959 & .452 & 1.759 & .090 \\
\hline
\end{tabular}

Residual standard error: 1.699 on 38 degrees of freedom; Multiple $R$-Squared: 0.40; Adjusted $R^{2}$ : 0.15 ; F-statistic: 1.616 on 7 and 31 DF, $p$ value $=.150 .\left({ }^{*} p<.05\right)$.

Table 5. Multiple Regression (Enter Mode): Impact of Biographical and Health Factors on Sports Accident Proneness

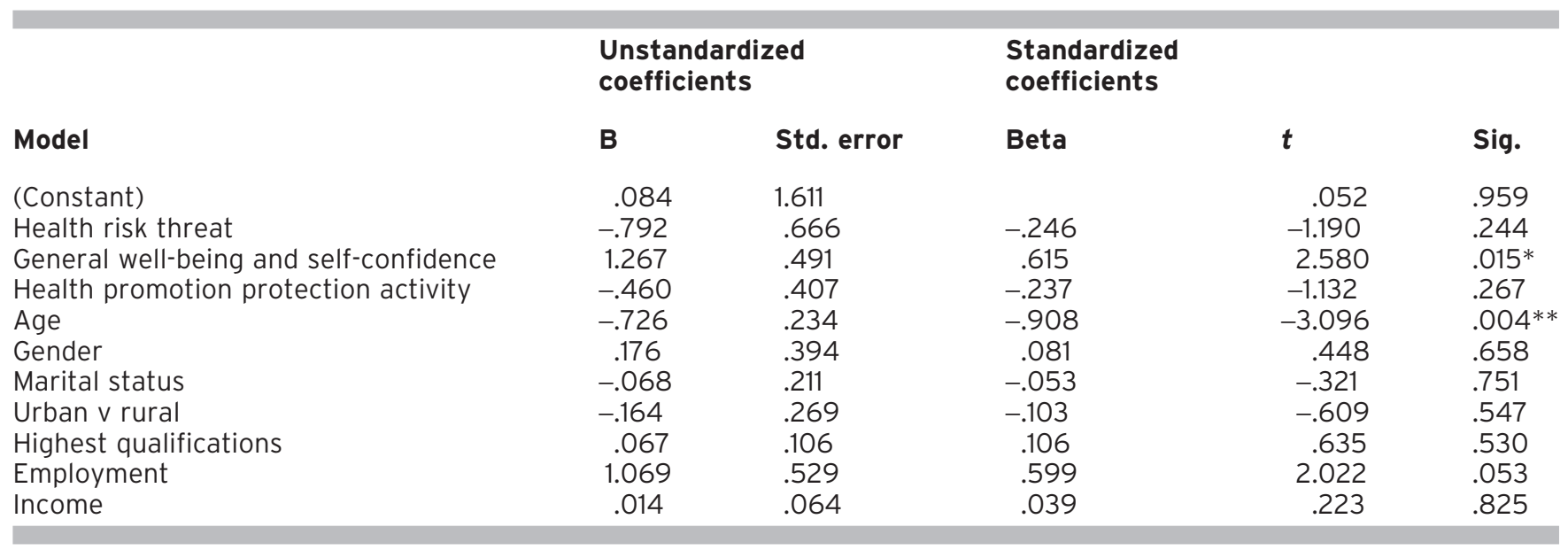

Residual standard error: 0.898 on 38 degrees of freedom; Multiple R-Squared: 0.43; Adjusted R2: 0.22; F-statistic: 2.088 on 7 and 31 DF, $p$ value $=.061 .(* p<.05 ; * *<<.01)$. 
as operationalized in this study, cannot be predicted with any degree of significance from any of the factors in this study.

\section{Discussion}

This study set out to investigate the relationship among accident proneness, FHP, and a number of biographical data/variables. The small size of the sample limits the possibility of making generalized statements in this regard, but a number of interesting trends emerged from the data, which have implications for further research in this area. The only biographical variable that significantly predicted accident proneness was age. The findings demonstrated that older respondents were less prone to accidents than were younger respondents. These findings share some similarities with those reported by Gauchard et al. (2006), who reported an association between a greater incidence of injuries with certain individual and occupational factors. These included younger age, first year in job, having a sleep disorder, and smoking. The association between younger age and work-related injuries was also reported by Bhattacherjee et al. (2003), who examined the relationships of job and individual characteristics to occupational injuries. The researchers reported that high risk of occupational injuries was found in individuals under the age of 30 . One explanation put forward for this is that young people have less experience, which can influence the occurrence of injury. Interestingly, Bhattacherjee et al.'s study also found that men had a higher risk of injury than women, a finding that was not supported in the present study.

Another noteworthy result from our study was that positive FHPs were associated with greater accident proneness. This appears counterintuitive until one considers the fact that, while the prevalence of accidents in this sample was $40 \%$ (51 accidents), almost half of these $(n=23)$ were sports-related. In fact, a positive link between frequency of sports injuries and the general well-being and self-confidence factor of functional health was identified. Encouraging sports can be regarded as a positive and useful strategy for increasing physical activity (and therefore health) among the population, but public health warnings have alluded to increasing rates of injuries in the last few years (Dumas \& Laforest, 2009). Ensuring healthy outcomes in sports has many challenges. For example, sensitizing individuals to issues about health and injury reduction/prevention is difficult if steps are not taken by them to protect themselves from injury. Yannick, Deroche, Brewer, Caudroit, and Le Scanff (2009, p. 673) suggest that risky practices or "failing to take precautions" can contribute to injury. Runners, for example, who do not warm up before running, or who allow insufficient recovery after an injury or train excessively, may be susceptible to running injuries. Such practices, these researchers point out, involve some form of modification in behavior. Visser et al. (2007) also emphasized that what they called "self-inflicted" injuries are due to clumsiness or risk-taking and should be considered the core of accident proneness. It should be noted that risktaking behavior and the irrationality that is at its basis hardly fits in with the cost-benefit approach of the health belief model (Rosenstock, 1966) in predicting health behavior. Therefore, to capture proneness to accidents in sports seems to require a rethinking of the relationship among health, behavior, and rationality. This may also have implications for the further development of measures of health, health behavior, and cognitions such as the FHPAST.

Beyond this, however, the findings are inconclusive due to the size and nonrepresentativeness of the sample. They are, however, indicative of a potential for the FHPAST to be used in the identification of proneness to accidents. Further research will be required to explore any such potential.

Some limitations of the study have already been noted. The response rate was very small. This is not surprising since poor response rates and technical difficulties are listed as some of the limitations of 
online surveys (Evans \& Mathur, 2005; Granello \& Wheaton, 2004). A second limitation concerns the gender distribution of the sample. The majority of the respondents $(67.3 \%, n=33)$ were female while only $(32.7 \%, n=16)$ were male. It is quite possible that accident rates and proneness to accidents are different between men and women, but with such small numbers, it is not possible for the authors to comment confidently on this aspect of the findings. It is also unclear as to what role, if any, is played by ethnicity as the sample demonstrated homogeneity in this regard. Finally, it is acknowledged that the sample was self-selecting and comprised of largely young graduates who might be expected to engage in activities such as sports that could predispose them to accidents.

\section{Conclusions and Recommendations}

Accidents, as indicated earlier in this article, are costly and can contribute to reduced productivity and increased human suffering. This, together with a desire to understand better the associations between accidents and other variables, strengthens the need for continued research in this area.

This pilot study explored the relationship among accident occurrence, biographical factors, and FHP using the FHPAST instrument among a group of university alumni. Although the sample was small, the findings provided an insight into the prevalence of accidents in this population and the correlations among proneness to accidents, functional health, and demographic/biographic variables. The findings suggest that the majority of accidents occurred in the home or were sports-related, and that there was no significant difference between the overall FHP of those who reported having had accidents and those who did not. However, one of the factors of the FHPAST, the general well-being and self-confidence factor, predicted more frequent sports accidents. The findings further demonstrated that of all the demographic/biographical factors examined, age group was the only one that loaded significantly on accident proneness, and that higher age predicted lower proneness to accidents. However, when sportsrelated accidents were excluded from the analysis, there was no significant relationship between age group and accident proneness.

Although the findings presented here cannot be generalized to other populations, they do, nonetheless, offer some useful insights into the relationship between health and accident proneness among a cohort of university graduates. It is possible that a larger sample may produce different findings, so from this perspective, the authors would support the view that further research to explore the relationship between proneness to accidents and other associated variables should continue using larger samples from different populations. This would also facilitate comparisons between graduate and nongraduate populations to explore whether the level and types of accidents differ. Finally, the findings also suggest that accident proneness may not be a unitary concept, and that distinctions between types and context of accidents need to be included in future research.

\section{References}

Altarac, M., Gardner, J. W., Popovich, R. M., Potter, R., Knapik, J. J., \& Jones, B. H. (2000). Cigarette smoking and exercise-related injuries among young men and women. American Journal of Preventive Medicine, 18(3S), 96-102.

Barkley, R. A. (2002). Major life activity and health outcomes associated with attention deficit/hyperactivity disorder. Journal of Clinical Psychiatry, 63(Suppl. 12), 10-15.

de Barros, A. L. B. L., Michel, J. L. M., \& da Nobrega, M. L. (2003). Translation, utilization, and psychometric properties of the Functional Health Pattern Assessment Screening Tool with patients in Brazil. International Journal of Nursing Terminologies and Classifications, 14(Suppl. s4), 17.

Bhattacherjee, A., Chau, N., Sierra, C. O., Legras, B., Benamghar, L., Michaely, J. P.,... Mur, J. M., \& Lorhandicap Group. (2003). Relationships of job and some individual characteristics to occupational injuries in employed people: A community-based study. Journal of Occupational Health, 45(6), 382-391.

Bhushan, B., \& Khan, S. M. (2006). Laterality and accident proneness: A study of locomotive drivers. Laterality, 11(5), 395-404.

Blasco, R. D., Prieto, J. M., \& Cornejo, J. M. (2003). Accident probability after accident occurrence. Safety Science, 41, 481-501. 
Bruckner, T. A., Brown, R. A., \& Margerison-Zilko, C. (2011). Positive income shocks and accident deaths among Cherokee Indians: A natural experiment. International Journal of Epidemiology, 40(4), 1083-1090. doi:10.1093/ije/dyr073

Buglar, M., White, K., \& Robinson, N. (2010). The role of self-efficacy in dental patients' brushing and flossing: Testing an extended health belief model. Patient Education and Counseling, 78, 269272.

Dumas, A., \& Laforest, S. (2009). Skateparks as a health-resource: Are they as dangerous as they look? Leisure Studies, 28(1), 19-34.

Engel, H. O. (1991). Accident proneness and illness proneness: A review. Journal of the Royal Society of Medicine, 84(3), 163-164.

Evans, J. R., \& Mathur, A. (2005). The value of online surveys. Internet Research, 15(2), 195-219.

Gauchard, G. C., Mur, J. M., Benamghar, L., Dehaene, D., \& Chau, N. (2006). Determinants of accident proneness: A case-control study in railway workers. Occupational Medicine, 56(3), 187-190.

Gordon, M. (1994). Nursing diagnosis: Process and application (3rd ed.). St. Louis: Mosby.

Granello, D. H., \& Wheaton, J. E. (2004). Online data collection strategies for research. Journal of Counseling and Development, 82(4), 387-393.

Hingson, R., \& Howland, J. (1993). Alcohol and non-traffic unintended injuries. Addiction, 88, 877-883.

Hrymak, V., \& Pérezgonzález, J. D. (2007). The costs and effects of workplace accidents: Twenty case studies from Ireland. Health and Safety Authority Research Series. Dublin, Ireland: School of Food Science and Environmental Health at Dublin Institute of Technology.

Iverson, H., \& Rundmo, T. (2002). Personality, risky driving and accident involvement among Norwegian drivers. Personality and Individual Differences, 33, 1251-1263.

Jones, D. (2002). Establishing the psychometric properties of the FHPAST: Use in practice. Journal of Japan Society of Nursing Diagnosis, 7(1), 12-17.

Jones, D., \& Foster, F. (1999). Further development and testing of a functional health pattern assessment screening tool. In M. J. Rantz \& P. LeMore (Eds.), Classification of nursing diagnoses: Proceedings of the thirteenth conference, North American Nursing Diagnosis Association. Celebrating the 25th anniversary of NANDA (pp. 328-337). Glendale, CA: CINAHL Information Systems.
Jones, D., \& Foster, F. (2006). Functional health patterns. In J. J. Fitzpatrick \& M. Wallace (Eds.), Encyclopedia of nursing research (2nd ed., p. 222). New York: Springer.

King, W. J., LeBlanc, J. C., Barrowman, N. J., Klassen, T. P., BernardBonnin, A. -C., Robitaille, Y.,...Pless, I. B. (2005). Long term effects of a home visit to prevent childhood injury: Three year follow up of a randomized trial. Injury Prevention, 11, 106109.

Marušič, A., Musek, A., \& Gudjonsson, G. (2001). Injury proneness and personality. Nordic Journal of Psychiatry, 55(3), 157161.

Mossink, J., \& De Greef, M. (2002). Inventory of socioeconomic costs of work accidents. European Agency for Safety and Health at Work. Retrieved from http://osha.europa.eu/en/ publications/reports/207/view?searchterm=Inventory\%20of \%20Socioeconomic\%20Costs\%20of\%20Work\%20Accidents Accessed January 172011.

Neeleman, J. (2001). A continuum of premature death. Metaanalysis of competing mortality in the psychosocially vulnerable. International Journal of Epidemiology, 30(1), 154-162.

Niza, C., Silva, S., \& Lima, M. L. (2008). Occupational accident experience: Association with workers' accident explanation and definition. Safety Science, 46(6), 959-971.

Pavan, C., Grasso, G., Constantini, M. V., Pavan, L., Masier, F., Azzi, M. F.,... Vingigni, V. (2009). Accident proneness and impulsiveness in an Italian group of burn patients. Burns, 35(2), 247-255.

Rosenstock, I. M. (1966). Why people use health services. Milbank Memorial Fund Quarterly, 44(3), 94-127.

Visser, E., Pijl, Y. J., Stolk, R. P., Neeleman, J., \& Rosmalen, J. G. (2007). Accident proneness, does it exist? A review and metaanalysis. Accident; Analysis and Prevention, 39, 556-564.

Vollrath, M., \& Torgersen, S. (2002). Who takes health risks? A probe into eight personality types. Personality and Individual Differences, 32, 1185-1197.

af Wåhlberg, A., \& Dorn, L. (2009). Bus driver accident record: The return of accident proneness. Theoretical Issues in Ergonomics Science, 10(1), 77-91.

Yannick, S., Deroche, T., Brewer, B. W., Caudroit, J., \& Le Scanff, C. (2009). Predictors of perceived susceptibility to sport-related injury among competitive runners: The role of previous exercise, neuroticism, and passion for running. Applied Psychology, 68(4), 672-687. 